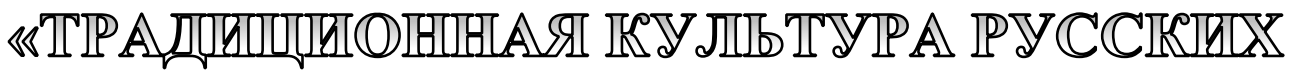

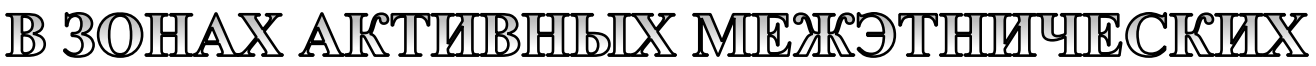

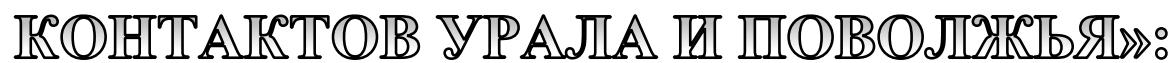

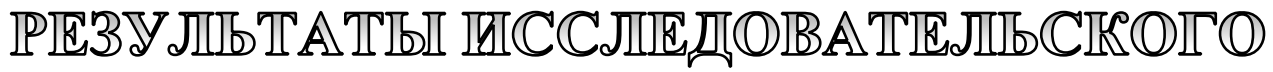 IIIPOEIRTA *
}

А.В. Черных, Пермский федеральный исследовательский центр УрО РАН

М.С. Каменских, Пермский федеральный исследовательский чентр УрО РАН

\section{Для цитирования:}

Черных А.В., Каменских М.С. «Традиционная культура русских в зонах активных межэтнических контактов Урала и Поволжья»: результаты исследовательского проекта // Вестник Пермского федерального исследовательского центра. - 2021. - № 1. - С. 74-80. https://doi.org/10.7242/2658-705X/2021.1.7

\begin{abstract}
Представлено краткое описание этнологического и этнолингвистического исследовательского проекта «Традиционная культура русских в зонах активных межэтнических контактов Урала и Поволжья», реализуемого сектором этнологических исследований Отдела истории, археологии и этнографии ПФИЦ УрО РАН.

Описаны полученные в рамках первых двух лет реализации проекта результаты, связанные со спецификой языка и традиционной культуры русских в различных территориях Урала и Поволжья, особенностями старообрядческой традиции региона, а также со спецификой этнической истории, материальной и духовной культуры различных локальных групп русских Урала и Поволжья.
\end{abstract}

Ключевые слова: русские, традиционная культура, говоры, костюм, диалекты, обряды, этнографические группы.

\section{Введение}

Русские - один из самых многочисленных народов Евразии, крупнейший по численности народ России. По итогам 2010 года в нашей стране проживало 111016896 русских, или 80,9\% населения России [6]. В обширном регионе Урала и Поволжья с его многонациональным составом русские также составляют большинство (более $80 \%$ населения). Все это определяет актуальность изучения языка, традиционной культуры и современных этнокультурных процессов региона. Данная территория является зоной интенсивного многовекового экономического и этнокультурного взаимодействия славянского, тюркских и финноугорских народов. В этой связи выявление этапов миграции русского населения, осо-

\footnotetext{
* «Исследование выполнено за счет гранта Российского научного фонда (проект №19-18-00117 «Традиционная культура русских в зонах активных межэтнических контактов Урала и Поволжья»).
} 
бенностей отдельных групп русских в Урало-Поволжье, их взаимодействие с другими народами представляют большой интерес не только с точки зрения этнографии, но и с позиции изучения общей истории освоения и развития региона.

Принято выделять несколько волн миграции русского населения в данный регион. Все они были обусловлены особенностями исторического развития и становления российской государственности. По этой причине русское население Урала и Поволжья не было однородным. Традиционно принято выделять несколько этнографических групп русских. Территории Урала и Поволжья известны жителям Русского Севера уже с XI в., именно тогда в летописях появляются упоминания о Перми, с которой русская колонизация начала поступательное движение на восток [1, с. 214-220]. Основу русского населения в регионе на этом этапе заложили выходцы из районов Русского Севера. B XIV-XV веках складываются очаги русского старожильческого населения, значительное усиление миграции фиксируется после вхождения Казанского ханства и подчинявшихся ему народов в состав Русского государства в XVI веке [20, с. 90-91].

C середины XVII века Урал принял миграционную волну русских, связанную с расколом Русской церкви, переселение в регион старообрядческого населения продолжалось в течение двух веков. По числу старообрядческого населения, например, Пермская губерния к концу XIX в. занимала одно из первых мест в России [20, с. 9091]. В XVIII веке возникновение горной металлургии на Урале происходило при прямом участии местного населения, прежде всего русских крестьян. Из местного крестьянского населения формировались кадры работных людей для заводов. Одновременно появление на Среднем Урале заводов и заводских поселений обусловило приток нового населения из центральных промышленных районов России [25, с. 6165]. Формирование русского населения в последующие периоды происходило в основном за счет внутренних миграций.
Неоднородность русской культуры, обусловленная характером ее распространения, многообразие вариантов ее существования, как внутри, так и вне России, все чаще привлекает внимание исследователей. Следует отметить, что имеющиеся на сегодняшний день исторические труды достаточно полно описывают этническое и культурное развитие проживающих в регионе татар, марийцев, мордвы, коми-пермяков, удмуртов, но в меньшей степени раскрывают этнические особенности русских в этих регионах, особенно в республиках Поволжья [28]. Между тем русская культурная традиция в среде народов Урала и Поволжья, оказав свое влияние на их культуры, сохранила и своеобразно реализовала архаический славянский пласт с учетом специфики региона. Одновременно под влиянием тюркской и финно-угорской этнокультурных доминант она претерпела трансформацию ряда комплексов.

В 2019 году коллектив пермских этнографов сектора этнологических исследований Отдела истории, археологии и этнографии ПФИЦ УрО РАН получил грант Российского научного фонда (РНФ) на реализацию исследовательского проекта «Традиционная культура русских в зонах активных межэтнических контактов Урала и Поволжья» [12]. Реализация проекта в 2019 и 2020 годах позволила добиться ряда существенных результатов, которые будут представлены в рамках данной статьи.

Целью проекта являлось изучение этнокультурного развития русского населения на территориях Урала и Поволжья, рассматриваемых в качестве особой историко-этнографической области России. Предметом исследования стала модификация русской культурной традиции, вызванная культурной адаптацией русских переселенцев к образу жизни «коренных» народов исследуемых территорий, саморазвитие традиции в новых условиях, ее варьирование в современной динамично меняющейся социокультурной среде.

На первом этапе авторским коллективом проводилась работа по расшифровке и систематизации источникового мате- 
риала, включению его в лексические картотеки и готовящиеся издания. В частности, организовано изучение коллекций и фотофиксация в архивных фондах Института этнологии и антропологии РАН (г. Москва), в Национальном музее Республики Татарстан, Российском этнографическом музее, Коми-Пермяцком краеведческом музее, Пермском краеведческом музее, Пермской государственной художественной галерее, Соликамском краеведческом музее, Добрянском краеведческом музее, Кунгурском историкокультурном и архитектурном музее-заповеднике и других. Также проведена работа в фондах центральных и региональных музеев России и Пермского края, в которых хранятся предметы традиционного русского костюма Прикамья.

В 2019 году из коллектива было сформировано несколько экспедиционных групп, которые проводили полевые исследования в разных регионах Урала и Поволжья - Республике Татарстан, КомиПермяцком округе Пермского края; в Пермском крае - в Лысьвенском, Сивинском, Куединском, Чердынском, Гайнском, Красновишерском районах, а также в Юрлинском, Верещагинском, Куединском, Лысьвенском, Нытвенском, Пермском, Чернушинском. В экспедициях были собраны материалы по традиционной культуре русских, которые, наряду с архивными источниками, легли в основу проекта. В 2020 году объем полевых исследований значительно сократился, однако также были проведены полевые экспедиционные работы в Куединском, Юрлинском, Верещагинском, Пермском районах Пермского края.

Изучение обрядности, верований, фольклора и языкового поведения русских данной зоны позволило выявить их культурно-языковое своеобразие среди других групп русского населения России. Одним из наиболее значимых результатов последних двух лет работы стал цикл публикаций по тематике традиционного русского костюма региона. Так, в 2019 году участниками проекта был подготов- лен и издан региональный словарь «Традиционный костюм народов Пермского края. Русские. Тематический словарь лексики одежды» [27]. В основу словаря легли записи живой народной речи жителей Пермского края разных лет (1949-2019), а также материалы из пермских диалектных и этнолингвистических словарей и фольклорно-этнографических сборников.

Всего в издании содержится более 2000 словарных статей, которые посвящены различным названиям одежды, головных уборов, обуви, рукавиц. Лексические данные словаря отражают состояние традиционного костюма жителей Пермского края с конца XIX по середину XX века. Особенности источниковой базы определили значительный объем издания, в котором представлено более 3000 лексических единиц, географический указатель содержит упоминание около 300 населенных пунктов региона. При подготовке словаря не только обрабатывался огромный массив источникового материала, но и разрабатывались теоретические вопросы его описания, модели толкований лексических единиц и методы их анализа. Особенность настоящего издания заключается и в большом количестве иллюстративного материала.

Развитие темы традиционного русского костюма продолжилось в монографии «Традиционный костюм народов Пермского края. Русские. Мужская одежда» [29]. В монографии на основе архивных, опубликованных, музейных и полученных в результате полевых исследований этнографических данных проанализированы особенности традиционного мужского костюма русского населения Пермского края. Основным для проведения исследования стал сравнительно-этнографический подход, который предполагал изучение традиционного костюма как явления материальной культуры. Автором рассмотрены особенности каждого из элементов костюма, отдельные производственные, праздничные и обрядовые комплекты одежды, специфика развития костюма на протяжении второй половины XIX - начала XX века, локальное своеоб- 
разие мужской одежды отдельных районов. Монография включает рисунки кроя, фотографии и иллюстрации, отражающие особенности регионального комплекса мужской одежды. Издание включает 14 авторских листов текста и более 1000 иллюстраций из полевых материалов и музейных коллекций.

Еще одним итогом многолетних исследований и сбора фольклорного и лингвистического материала стала подготовка и издание двух этнолингвистических словарей.

Изданный в 2019 году «Этнодиалектный словарь мифологических рассказов Пермского края. Ч.1. Люди со сверхъестественными свойствами» [19] раскрывает один из значимых пластов народной демонологии Пермского Прикамья - лексику о людях со сверхъестественными способностями. Среди таких персонажей в Пермской мифологии выделяются как классические - колдун и знахарь, так и персонажи, относимые народным сознанием к этой группе на основании признака «не свой, чужой». В основе концепции словаря лежит идея наиболее полного и адекватного отражения мифологических представлений исследуемого региона. Словарь показывает, что данные диалектных словарей и мифологические тексты Пермского края свидетельствуют о мотивационном многообразии номинаций тайного знания, которым обладают ритуальные специалисты.

Данный словарь относится к категории дифференциальных в том смысле, что в него входит не вся лексика мифологических рассказов, а только та, которая отражает сведения о мифологических персонажах, их характеристиках, функциях, предметах и т.п., т.е. «культурно нагруженные» единицы. Однако этот словарь не относится и к группе чисто диалектных, так как он включает и общеупотребительные слова (волшебник, знахарь, колдун, лекарь и т.п.), встречающиеся в пермских мифологических текстах. Особенности источниковой базы определили значительный объем настоящего словаря, в котором представлено более 3000 лексических единиц, геогра- фический указатель содержит упоминание около 300 населенных пунктов региона.

В 2020 году завершена работа по подготовке и изданию «Словаря мортальной лексики, фразеологии и символики русских говоров Прикамья» [22]. В нем дано описание лексики и фразеологии диалектной речи русского населения Пермского края с семантикой мортальности (обращенных к теме смерти и смежным с ней понятиям), предпринята попытка характеристики народной символосферы «Смерть». Его основу составляют полевые материалы, собранные авторами-составителями во второй половине XX - начале XXI века на территории Прикамья. В Словаре дается истолкование терминов похоронно-поминальной традиции, приводится лингвокультурологический комментарий диалектной лексики и фразеологии, обращенной к представлениям о конечности человеческой жизни, дан анализ происхождения обрядовой терминологии, истоков народной мортальной символики. Всего в словарь вошло более 600 лексических номинаций и 650 фразеологических единиц.

Работа по составлению словарей будет продолжена. Результаты экспедиционных работ в Чердынском, Красновишерском, Соликамском, Гайнском и других северных районах Пермского края лягут в основу очередного тома пермского диалектного словаря - «Словаря русских говоров севера Пермского края».

В рамках проекта проведены исследования среди старообрядческого населения Урала, собраны материалы об особенностях языка и традиционной культуры старообрядческого населения региона [24]. Во время экспедиционных выездов исследовались старообрядческие говоры, собран материал (духовные стихи, мифологическая проза, рассказы о семейной, хозяйственной, календарной традиции), раскрывающий особенности и современное состояние фольклорной традиции и традиционной обрядности часовенных старообрядцев. При изучении старообрядчества исследовалась специфика отвлеченной лексики, лексико-фразеологические 
заимствования в старообрядческой речи [15], особенности традиции имянаречения, специфика фразеологии старообрядческих говоров Прикамья [13]. Проводились сбор и описание отдельных жанров старообрядческого фольклора (легенды, рассказы о сновидениях, о конце света), исследовались демонологические представления старообрядцев [16].

В отдельных статьях проанализированы материалы о специфике конфессиональной культуры редкого и малочисленного старообрядческого согласия - «по Кресту», или рябиновцев Нижней Камы. В статье о старообрядцах рябиновского согласия раскрываются особенности идентичности и конфессиональных традиций данной группы [25]. Полученные материалы также станут основой для подготовки в будущем этнолингвистического «Словаря лексики русских старообрядцев».

Кроме этого, в рамках проекта изданы научные статьи, подготовлены доклады о специфике разных групп русского населения. В частности, авторами освещены общие особенности русского населения региона и задачи изучения традиционной культуры на современном этапе, особенности обрядовой терминологии и паремиям в русских говорах [17]; исследованию животной и растительной символики, символики обрядовой пищи [14], бытовых предметов, крестьянских орудий труда и пр. посвящены несколько работ; исследованы отдельные аспекты комплекса рекрутской обрядности [31]. Ряд публикаций отражают особенности бытования современных мифологических рассказов и комплекса представлений о мифологических персонажах и знающих [2], названий, используемых в вокативной функции [3]; исследования посвящены особенностям лексики пермских говоров [5], семейной обрядности русских, посвящен изучению музейных коллекций [32]. Особенности развития и инкорпорации русской культуры $\mathrm{XX}$ века в условиях рассматриваемого региона раскрыты в статьях об оценках вклада русской культуры в советской идеологии 1930-х годов [7; с. 93-94], а также о судьбах «Русского Харбина» в Прикамье 1950-х годов [8]. В целом, за два года реализации проекта издано 3 монографии, 3 тематических словаря диалектной лексики, опубликовано 5 статей в журналах, индексируемых в базе данных Scopus, и Web of Science, 11 - в журналах списка ВАК, 25 статей, индексируемых в РИНЦ. Итоговое количество публикаций превысило число запланированных. Результаты исследований презентованы в 30 докладах на научных конференциях, в том числе Международных и Всероссийских, участники проекта выступали с пленарными и секционными докладами.

Результаты экспедиционного изучения русских Республики Татарстан уже получили освещение в ряде публикаций. В районе Нижней Камы (Республика Татарстан) изучены особенности костюмного комплекса одной из локальных традиций русских сел Лаишевского района [30], собран материал по особенностям идентичности, комплексов традиционной культуры, межэтнических взаимоотношений, конфессиональных традиций русского населения. В течение 2019 и 2020 годов. Проводилась работа по расшифровке и систематизации собранного материала, включению его в лексические картотеки и готовящиеся издания «Русские Республики Татарстан».

На 2021 год уже намечены основные направления работы - завершение монографического исследования о русских Республики Татарстан и двух диалектных словарей. Проведенные исследования позволят лучше представить особенности этнокультурных комплексов русских региона. А также выявить основные закономерности их появления. Выявление форм и характера идентичности русских, особенностей языка и традиционной культуры, межэтнического взаимодействия помогает раскрыть существенные аспекты этнических и этнокультурных процессов, выявить механизмы развития и взаимодействия и возможности координировать и влиять на эти процессы, в том числе в рамках социально-экономической, культурной и образовательной политики. 


\section{Библиографический список}

1. Головнев А.В. Феномен колонизации. - Екатеринбург: УрО РАН, 2015. 592 с.

2. Гранова М.A. Мотивационный анализ названий духов-«хозяев» локусов (на материале русских говоров Пермского края) // Филологические заметки - 2020. - Т. 18. - № 2. - С. 49-74.

3. Гранова М.A. Названия духа-«хозяина» дома, используемые в вокативной функции (по данным мифологических текстов Пермского края) // Лексический атлас русских народных говоров (материалы и исследования) 2020 / отв. ред. С.А. Мызников. - СПб.: ИЛИ РАН, 2020. - С. 173-194.

4. Гранова М.А., Русинова И.И. Способы облегчения смерти колдуна (на материале русских мифологических рассказов Пермского края) // Традиционная культура. - 2020. - № 1. - Т. 21. - С. 136-148.

5. Зверева Ю.В. Лексика, характеризующая одежду по особенностям кроя, в пермских говорах // Славянская традиционная культура и современный мир: материалы Междунар. науч. конф. - М. Пермь, 2020. Вып. 19.

6. Итоги Всероссийской переписи населения 2010 [Электронный ресурс]: Росстат. URL.: http://gks.ru/free_doc/new_site/perepis2010/croc/perepis_itogi1612.htm (дата обращения: 30.09.2020).

7. Каменских М.С. «Русский поворот» в национальной политике СССР начала 1930-х годов: оценки отечественной и зарубежной историографии // Вестник ПФИЦ УрО РАН. - 2019. - № 4. - С. $93-97$. DOI: $10.7242 / 2658-705 X / 2019.4 .10$.

8. Каменских М.С. Рожденные в Китае: судьбы русских репатриантов из Китая в Прикамье 1930-1950-х годов // Вестник ПФИЦ УрО РАН. - 2020. - № 4. С. 93-99. DOI: https://doi.org/10.7242/2658-705X/2020.4.9.

9. Каменских М.С. Советская национальная политика в 1920-1930-е годы в современной отечественной и зарубежной историографии: основные тенденции // «Вестник Пермского университета», серия «История». - 2020. - № 2. - C. 57-66. DOI: 10.17072/2219-3111-2020-2-57-66.

10. Каменских М. С., Черных А.В. Русские Перми: история и культура // - СПб.: «Маматов», 2015. - 64 с.

11. Народы Пермского края: этническая история и современное этнокультурное развитие. Словарьсправочник. - СПб.: Маматов, 2014. - 416 с.

12. Перечень проектов, поддержанных по итогам конкурса 2019 года на получение грантов Российского научного фонда по мероприятию «Проведение исследований на базе существующей научной инфраструктуры мирового уровня» Президентской программы исследовательских проектов, реализуемых ведущими учеными, в том числе молодыми учеными // https://rscf.ru/upload/iblock/4aa/4aac73aae67a90373ecbb82527dda814.pdf.

13. Подюков И.А. Абстрактное слово в старообрядческих говорах Пермского края как средство выражения представлений о мире и вере // Вестник Пермского университета. Российская и зарубежная филология. - 2020. - Т. 12. - Вып. 1. - С. 285-300.

14. Подюков И.А. Обрядовая терминология в русских говорах Прикамья: устойчивость и вариативность // Социо- и психолингвистические исследования. - 2019. - Вып. 7. - С. 116-120.

15. Подюков И.А. Особенности фразеологического состава пермских старообрядческих говоров. // Вестник РУДН. Сер. Теория языка. Семиотика. Семантика. - 2020. - Т. 11. - № 2. - С. $285-300$.

16. Подюков И.А. Эсхатологические образы в живой речи современных старообрядцев Пермского Прикамья // Известия Уральского федерального университета. Сер. 2, Гуманитарные науки. - 2020. Т. 22. - № 1 (196). - С. 156-172.

17. Подюков И.А., Свалова Е.Н. Паремия в русских народных говорах Прикамья: семантика и прагматика. - СПб.: Маматов, 2019. - 224 с.

18. Русинова И.И. Названия магического знания (на материале мифологических текстов Пермского края) // Севернорусские говоры. - 2019. - Вып. 18. - С. 298-317.

19. Русинова И.И. Черных А.В. «Этнодиалектный словарь мифологических рассказов Пермского края. Ч.1. Люди со сверхъестественными свойствами». - СПб.: Маматов, 2019. - 832 с.

20. Русские // Народы России: Атлас культур и религий. - М.: Феория, 2011. - С. 90-91.

21. Свалова Е.Н. Запреты и предписания в речевой культуре пермского старообрядчества // Вестник Пермского университета. Российская и зарубежная филология. - 2020. - Т. 13. - Вып. 3. - С. 71-79.

22. Словарь мортальной лексики, фразеологии и символики русских говоров Прикамья / С.Ю. Королева [и др.]. - СПб.: Маматов, 2014. - 352 с.

23. Черных A.B. Народы Пермского края. История и этнография. - Пермь, 2007. - 296 с.

24. Черных A.B. Общие наименования старообрядцев в диалектной речи русского населения Пермского края // Известия Уральского федерального университета. Сер. 2. Гуманитарные науки. - 2020. - Т. 22. - № 1. (196). - С. 141-155.

25. Черных A.B., Вострокнутов А.В. Идентичность и конфессиональные маркеры старообрядцев «согласия по кресту» нижней Камы по материалам этнографических экспедиций // Уральский исторический вестник. - 2020. - № 3 (68). - С. 26-34. 
26. Черных А.В., Каменских М.С., Белавин А.М. Этническая история Пермского края // Народы Пермского края: этническая история и современное этнокультурное развитие. Словарь-справочник. - СПб.: Маматов, 2014. - С. 39-82.

27. Черных А.В., Русинова И.И., Зверева Ю.В. Традиционный костюм народов Пермского края. Русские. Тематический словарь лексики одежды. - СПб.: 2019. - 432 с.

28. Черных A.B. Русские Поволжья и Приуралья: этнокультурные особенности и перспективы изучения // Традиционная культура. - 2019. - № 5. - С. 13-22.

29. Черных А.В. Традиционный костюм народов Пермского края. Русские. Ч. 2. Мужская одежда. СПб.: Маматов, 2020. - 540 c.

30. Чернышева Ю.С. Комплекс послесвадебных ритуалов в русских традициях Нижней Камы // Сб. науч. ст. XVI Bсерос. науч.-практ. конф. «Национальные культуры Урала: история, современное состояние, перспективы». - Екатеринбург, 2020.

31. Чернышева Ю.С. Ритуалы, направленные на благополучное возвращение домой, в рекрутской обрядности русских Прикамья // Вестник научной ассоциации студентов и аспирантов исторического факультета Пермского государственного гуманитарно-педагогического университета. Cep. Studis historica juvenum. - 2020. - № 1 (16).- С. 71-75.

32. Чернышева Ю.С., Собянина Т.И. Этнографические коллекции русских музея археологии и этнографии Пермского Предуралья ПГГПУ // Труды Камской археолого-этнографической экспедиции. Вып. XV: Хозяйственно-культурный облик Предуралья: сб. науч. тр. / под общ. ред. Н.Б. Крыласовой; Перм. гос. гуманит.-пед. ун-т. - Пермь. - 2019. - С. 117-120.

\title{
TRADITIONAL CULTURE OF RUSSIANS IN AREAS OF ACTIVE INTERETHNIC CONTACTS IN THE URALS AND THE VOLGA REGION: RESULTS OF A RESEARCH PROJECT
}

\author{
A.V. Chernikh, M.S. Kamenskikh \\ Perm Federal Research Center UB RAS
}

\section{For citation:}

Chernikh A.V., Kamenskikh M.S. Traditional culture of Russians in areas of active interethnic contacts in the Urals and the Volga region: results of a research project // Perm Federal Research Center Journal. - 2021. - № 1. - P. 74-80. https://doi.org/10.7242/2658-705X/2021.1.7

The article presents a brief review of ethnological and ethno-linguistic research project «Traditional culture of Russians in areas of active interethnic contacts in the Urals and the Volga region» carried out by the sector of ethnological research of the Department of History, Archeology and Ethnography of PFRC UB RAS. It describes the results of the project obtained during the first 2 years and connected with the specific features of the language and traditional culture of Russians in different territories of the Ural and the Volga region, the particularities of the Old Believers' customs of the region as well as the specificity of ethnic history, material and spiritual culture of various local groups of Russians in the Urals and the Volga region.

Keywords: Russians, traditional culture, subdialects, costume, dialects, rituals, ethnographic groups.

\section{Сведения об авторах}

Черных Александр Васильевич, доктор исторических наук, член-корреспондент РАН, старший научный сотрудник отдела истории, археологии и этнографии, Пермский федеральный исследовательский центр УрО РАН («ПФИЦ УрО РАН»), 614900, г. Пермь, ул. Ленина, 13А; e-mail: atschernych@yandex.ru

Каменских Михаил Сергеевич, кандидат исторических наук, заведующий сектором этнологических исследований отдела истории, археологии и этнографии, «ПФИЦ УрО РАН»; e-mail: pomidorrr@mail.ru 